\title{
Three-dimensional Digital Documentation and Accuracy Analysis of the Choijin Lama Temple in Mongolia
}

\author{
Young Hoon Jo 1,*, Jun Huyn Park', Eunki Hong², Wook Han ${ }^{2}$ \\ ${ }^{1}$ Department of Cultural Heritage Conservation Sciences, Kongju National University, Gongju 32588, Korea \\ ${ }^{2}$ Architectural Heritage Division, National Research Institute of Cultural Heritage, Daejeon 34122, Korea
}

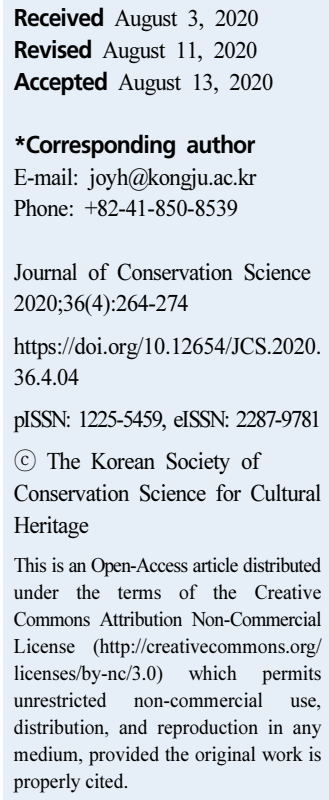

\begin{abstract}
The Choijin Lama Temple is a representative example of 19th- to 20th-century architecture. The temple has been damaged by various development pressures and the effect of a harsh continental climate. This study digitalized the entire temple site using three-dimensional scanning to establish the basic data of conservational management and monitoring for spatial changes. A terrestrial laser scanning model of the temple was completed, which showed low registering error vectors (3.73 mm average) and dense point distances. Unmanned aerial vehicle (UAV) photogrammetry was also applied to verify its applicability to the spatial and environmental monitoring of the temple. The results showed that the overall point density of the UAV photogrammetry model is similar within a $10 \mathrm{~mm}$ resolution. The relatively low RMSE of UAV photogrammetry from the ground to the uppermost roof indicates the high applicability of integrating it with the terrestrial laser scanning model. The digital documentation of the Choijin Lama Temple is expected to have a great ripple effect on the documentation, conservation, and utilization of Mongolian cultural heritage sites.
\end{abstract}

Key Words Choijin Lama Temple, Mongolia, Three-dimensional scanning, Unmanned aerial vehicle photogrammetry, Digital documentation, Accuracy analysis

\section{INTRODUCTION}

In 2014, the National Research Institute of Cultural Heritage of Korea and the Mongolian Cultural Heritage Center discussed a joint documentation project of architectural heritages. The Korea-Mongolia Cultural Heritage Documentation Project began in 2015 with the two countries signing a memorandum of understanding to collaborate on making an engineering plan and performing a three-dimensional (3D) measurement of ancient architectural heritages (National Research Institute of Cultural Heritage, 2019). The Mongolian architectural heritages, which completed the documentation project in 2015, 2016, and 2017, are the Uuld Beisin Khuree Temple, Unstiin Khiid Temple, and Zayiin Khuree Temple, respectively.
The fourth architectural heritage site of the KoreanMongolian joint documentation project is the Choijin Lama Temple located in Ulaanbaatar, which has been designated by the Mongolian government as a national cultural heritage. The temple was constructed in 1903 but consumed to the ground during the same year. The original form of the temple has been maintained after its rebuilding in 1908. Although not considered as one of the oldest examples of Mongolian architecture, the temple retains great historical and cultural significance as a representative example of 19th- to 20thcentury architecture. Similar to most cultural heritages exposed to outside conditions, the temple has also been damaged by natural and artificial factors. The temple is particularly under various development pressures because it is situated in 
the downtown section of Ulaanbaatar and is being deteriorated by environmental changes resulting from the harsh continental climate zone. Accordingly, digital documentation is very important in conserving and maintaining the value of the Choijin Lama Temple (Kioussi et al., 2013; Wilson et al., 2018; Campiani et al., 2019; Jo and Hong, 2019; Dalkılıç and Nabikoğlu, 2020).

The important considerations for the digital documentation of a temple site are its entire space and the architectural styles of wooden buildings, particularly the arrangement of each wooden building, modern environment of the temple's surroundings, and complex brackets of the main temple. Considering these factors, to obtain the raw 3D original data of the Choijin Lama Temple, the details of the main building used as a museum must be precisely recorded at the same time as collecting spatial information about the overall site, including the arrangement of historical structures, based on absolute coordinates.

The 2015-2017 documentation projects focused on the 3D scanning of a single building. In contrast, this study digitalized the temple's entire area. Documenting the entire area, including wooden buildings, using digital technologies establishes the basic data for conservational management. Additionally, valuable monitoring data for comparing the changes in spatial arrangement and surroundings are expected to be obtained.

\section{MATERIALS AND METHOD}

The Choijin Lama Temple was built in 1904-1908 by Bogd Khan, the last theocrat ruler of Mongolia, for his brother, the State Oracle Lama Luvsankhaidav. The temple was shut down in 1938 and turned into a museum in 1942 and is still being used as a museum. All heritages in the temple site, except the brick wall with sculpted reliefs at the front, are composed of wooden buildings (National Research Institute of Cultural Heritage, 2019). Situated in the downtown section of Ulaanbaatar, the Choijin Lama Temple is
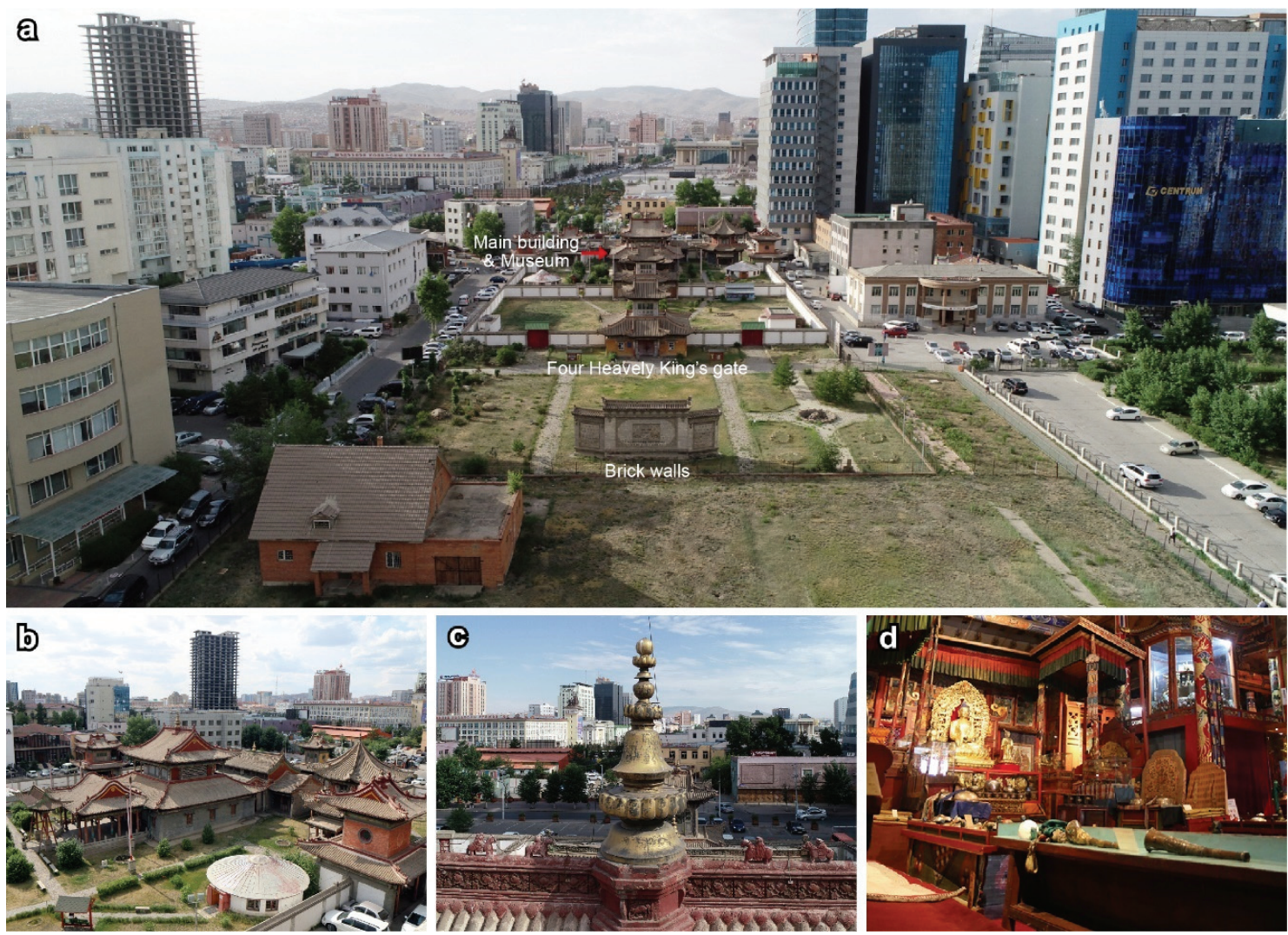

Figure 1. Field existence of the Choijin Lama Temple, Ulaanbaatar. (a) Temple layout and surrounding environments, (b) Main building, (c) A decoration installed at the apex of the roof, (d) Artifacts displayed in the main building. 
conveniently located for visitors; however, this central location is also a serious cause of concern for the temple's safety. The temple complex is towered over by skyscrapers and dangerously closely neighbored by parking lots (Figure 1a). Moreover, the wall, especially in the area around the Yadam building, is already heavily damaged. These issues must be addressed through continuous efforts to improve the temple's outdoor environment.

The most important buildings in this temple are the gate for the Four Heavenly Kings and the main building situated further north of it (Figure 1b). The dragons cavorting in clouds painted on a crimson background are visible across this Buddhist complex. A decoration was installed at the apex of the roof of the main building (Figure 1c), and the gilded bronze statue of Bodhisattva and Amitabha believed to have been made by disciples of Zanabazar during the 17th century. Silk thangka paintings, Buddhist sculptures made of different materials, clothes, and rubbings are also displayed (Figure 1d).

The Choijin Lama Temple is a historic site with a very high conservational value of surroundings, buildings, and artifacts. This study documented the spatial information of the entire temple site using long-range 3D scanning. Furthermore, detailed numerical information of the internal space of the main building was obtained through mid-range 3D scanning. An absolute coordinate was measured through the radio real-time kinematic (RTK) Global Navigation Satellite System and input into the scanning result. The basis data were then established for drawing the measuring plan and analyzing the shape. Additionally, the applicability of unmanned aerial vehicle (UAV) photogrammetry was examined through an accuracy analysis. Subsequently, the analysis results were compared with the terrestrial laser scanning results considering that the accuracy analysis has been widely used for the rapid spatial recording and monitoring of historic sites in the recent years (O’Driscoll, 2018; Ferraby and Powlesland, 2019; Jeong et al., 2020).

\section{RESULTS AND DISCUSSION}

\subsection{Ground control point survey}

The ground control points must be surveyed to convert the $3 \mathrm{D}$ scanning results based on relative spatial coordinates into absolute coordinates. Ground control points are generally surveyed using RTK, which can be divided into network and radio modes. The virtual reference station-based survey is currently not possible in Mongolia; hence, this study used the radio RTK mode (V90 Plus GNSS RTK System, Hi-Target, $\mathrm{CHN}$ ) to survey the ground control points. Accordingly, two GPS receivers were used: one at the base station and one at the rover unit. The base station in a fixed location generated GPS correction signals, whereas the rover unit receiving the correction signals changed its location to conduct a high-precision survey. The rover vehicle position was determined based on its position relative to the base station.

The GCPs selected for the Choijin Lama Temple were seven random locations (i.e., $\mathrm{CP} 1-\mathrm{CP} 7)$ free of obstacles with a clear field of view, instead of any specific and permanent landmarks. The results showed that the Choijin Lama Temple is located at $1303.96-1304.60 \mathrm{~m}$ altitude (Figure 2). In

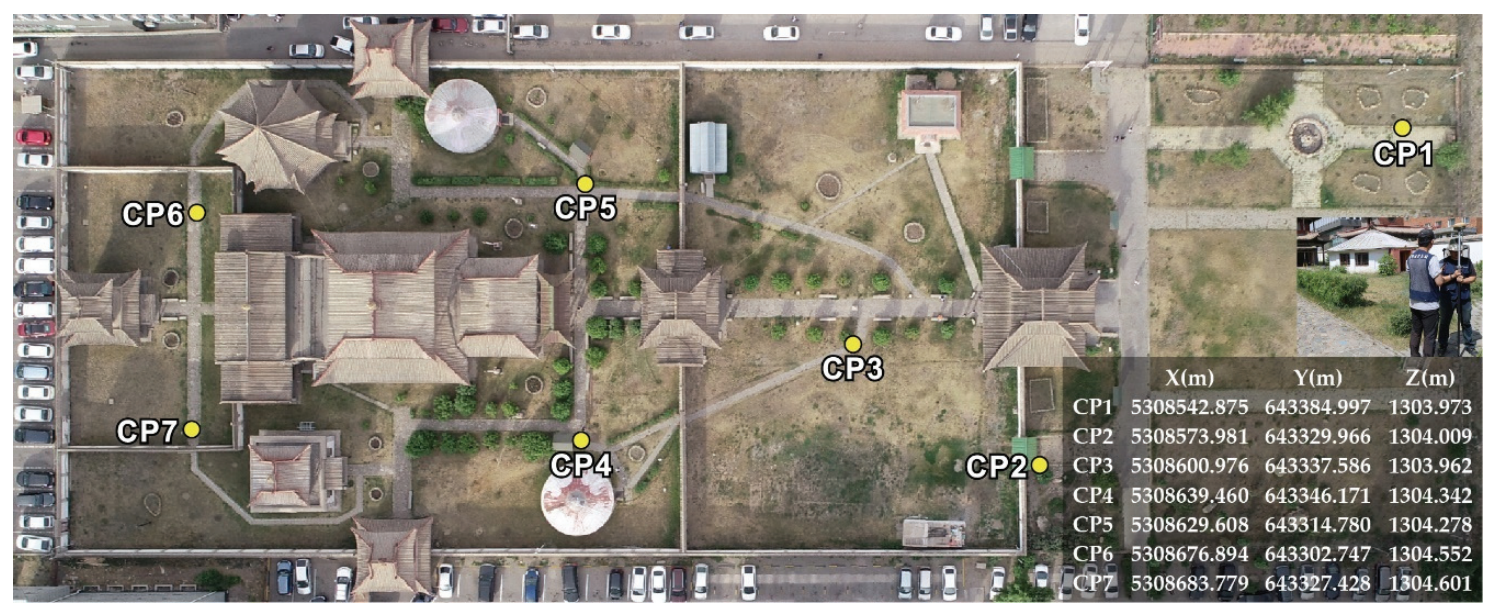

Figure 2. Seven ground control points (GCPs) and survey results of the Choijin Lama Temple. 
approximately $0.7 \mathrm{~m}$ of altitude difference, the site appears to be almost flat. Such ground control point information was used to correct the absolute position of the $3 \mathrm{D}$ model based on the terrestrial laser scanning model. This information was also used to create high-precision ortho-images of the Choijin Lama Temple and increase the accuracy and reliability of the topographic survey.

\subsection{Terrestrial laser scanning}

Terrestrial laser scanning was conducted to document the external and internal shapes of the Choijin Lama Temple. The device used for the digital documentation was a long- and mid-range 3D scanner based on time-of-flight ranging technology. The long-range scanner (ScanStation C10, Leica Geosystems, CHE) can acquire geometric data at a distance of $300 \mathrm{~m}$. The distance accuracy values in a single sigma at $1-50 \mathrm{~m}$ were $4 \mathrm{~mm}$. Furthermore, the mid-range scanner (BLK360, Leica Geosystems, CHE) can obtain geometric data at a distance of up to $60 \mathrm{~m}$. The distance accuracy values in a single sigma were $4 \mathrm{~mm}$ and $7 \mathrm{~mm}$ at $10 \mathrm{~m}$ and 20 $\mathrm{m}$, respectively. The field scan data were processed using Cyclone 9.2 by Leica.

Long-range scans were conducted in 149 outdoor locations selected by considering the scope of the survey and the degree of overlapping, whereas mid-range scans were conducted in 79 indoor locations inside the main temple. The Choijin Lama Temple is rather large in area; thus, a longrange scan was also conducted from tall buildings in its surroundings to collect as much roof-related data as possible. Furthermore, for the main building, which is a two-story structure with elaborate woodwork, scaffoldings and telescoping ladders were used to scan many blind spots and obtain as much numerical data as possible.
The point cloud data acquired in the field through $3 \mathrm{D}$ scans are unaligned raw shape data. Each scan image must be post-processed to construct a single merged digital model based on many raw scan data. Post-processing varies depending on the type of scanner, individual processing method, and preference program, but most often consists of four main steps, namely registering, filtering, merging, and optimizing (Jo and Lee, 2009; 2012). The 3D model of the Choijin Lama Temple was completed through the same processing method.

The reliability of a 3D model particularly depends on the registering result based on the iterative closest point algorithm (Yang et al., 2015; Guan et al., 2020). Therefore, this study calculated the registering error vectors between each scan data. The optimum registration was completed through error vector corrections. As a result of analyzing the registering errors, the internal scan data of the main building showed a distance of $2.80 \mathrm{~mm}$ (minimum) to $6.37 \mathrm{~mm}$ (maximum), with an average distance of $3.67 \mathrm{~mm}$, whereas the external scan data showed a distance of $2.70 \mathrm{~mm}$ (minimum) to $5.24 \mathrm{~mm}$ (maximum), with an average distance of $3.75 \mathrm{~mm}$. Furthermore, the error vectors of the internal and external total scan data had a normal distribution with a left-right symmetry centering on an average of $3.73 \mathrm{~mm}$. The error vector values were very similar to the distance accuracy of the 3D scanner, making it seem to have high reliability of registering results (Figure 3).

Merging was conducted after the registration. Subsequently, a single 3D model was completed. The reality effect of the entire temple site was raised by mapping the RGB texture. Figures 4 shows the scanning results of the topographic and morphological features of the entire temple site and depicts the scanning results providing the spatial information of the main building's interior. Finally, the values of the ground control points were entered into the optimized

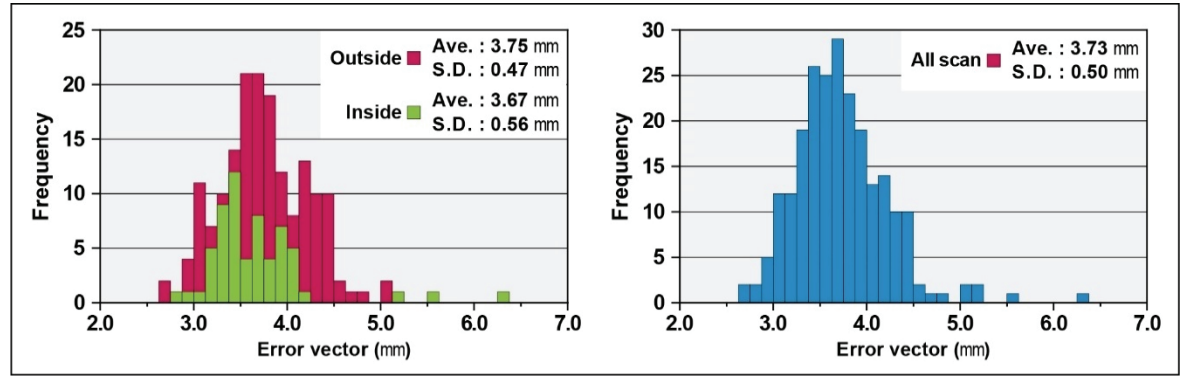

Figure 3. Distribution of the registering error vectors between each scan dataset. 
point cloud model. The Choijing Lama Temple was rearranged to the true north and had absolute positional information. The analysis of the average point distance for the representative sections showed that planar roofs A1 to A5 had distances of $6.4,9.9,44.9,4.8$, and $46.0 \mathrm{~mm}$, respectively, whereas the perpendicular sections B1 to B4 had a distance of $12.2,4.4,15.3$, and $4.0 \mathrm{~mm}$, respectively. The overall point density varied according to the scan position, direction, and overlap ratios (Figure 5).

The terrestrial laser scanning results of the surroundings of the Choijin Lama Temple showed a four-lane two-way road that runs along its south side and smaller roads near the building clusters along its east, west, and north sides. Many tall buildings are found in all directions, with a mega-tall skyscraper, a major landmark of Ulaanbaatar, situated north of the temple. The temple located in an area

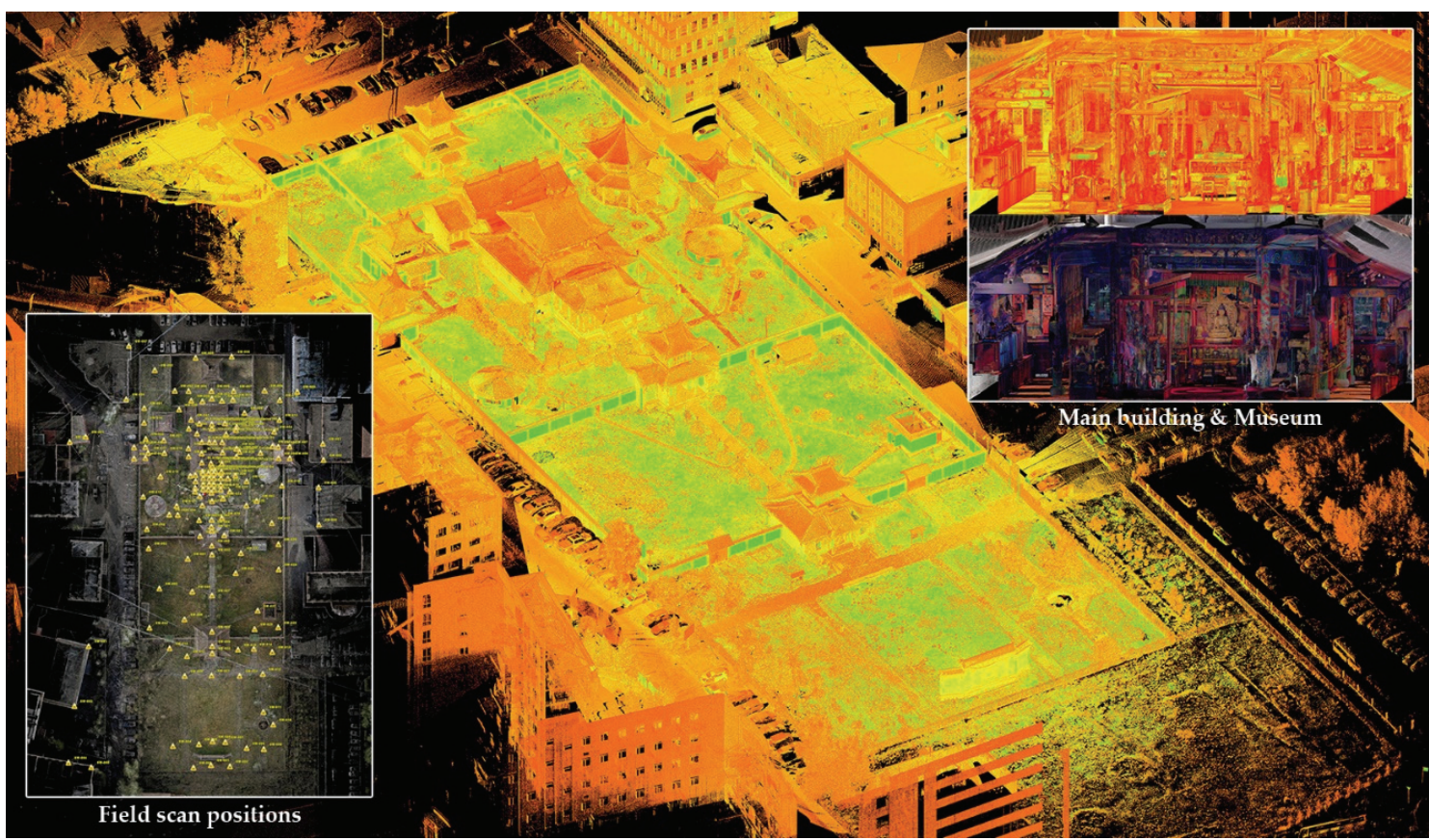

Figure 4. Completed 3D model showing spatial information of the entire temple site and the main building's interior.

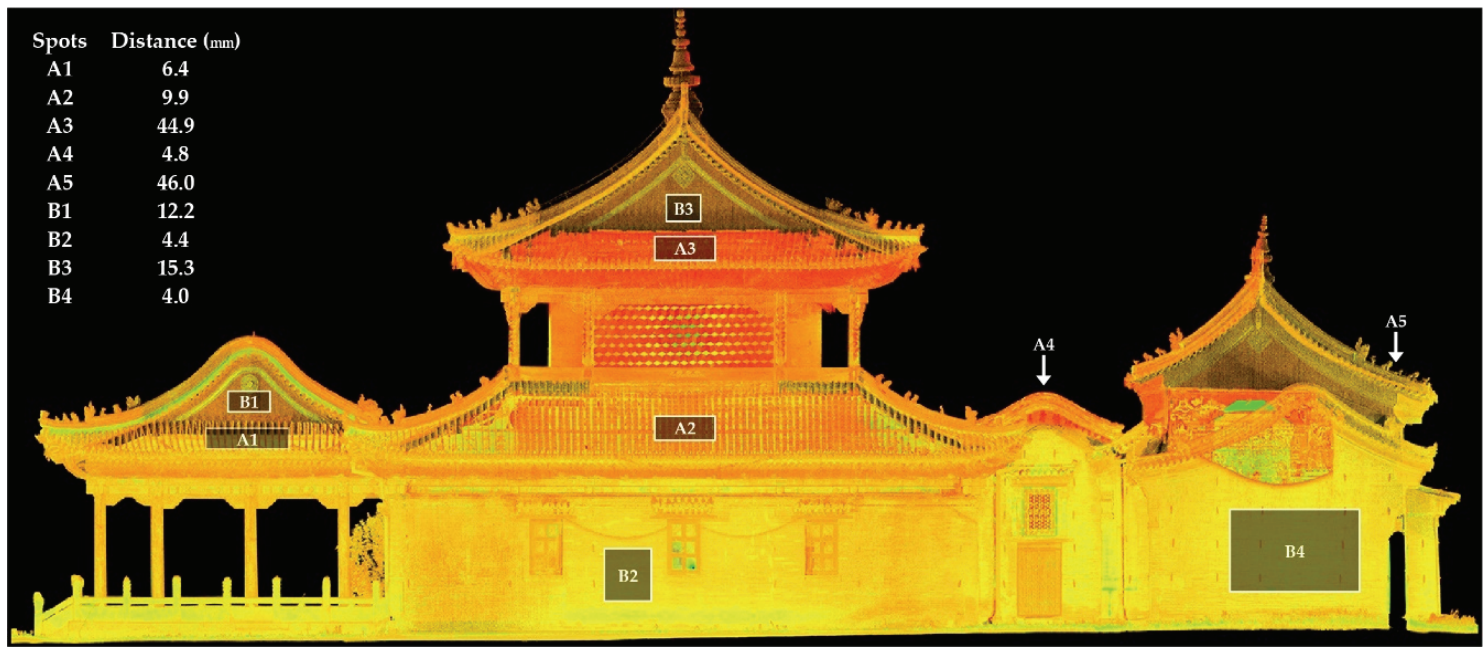

Figure 5. The average point distance of terrestrial laser scanning for the representative sections of the main building. 


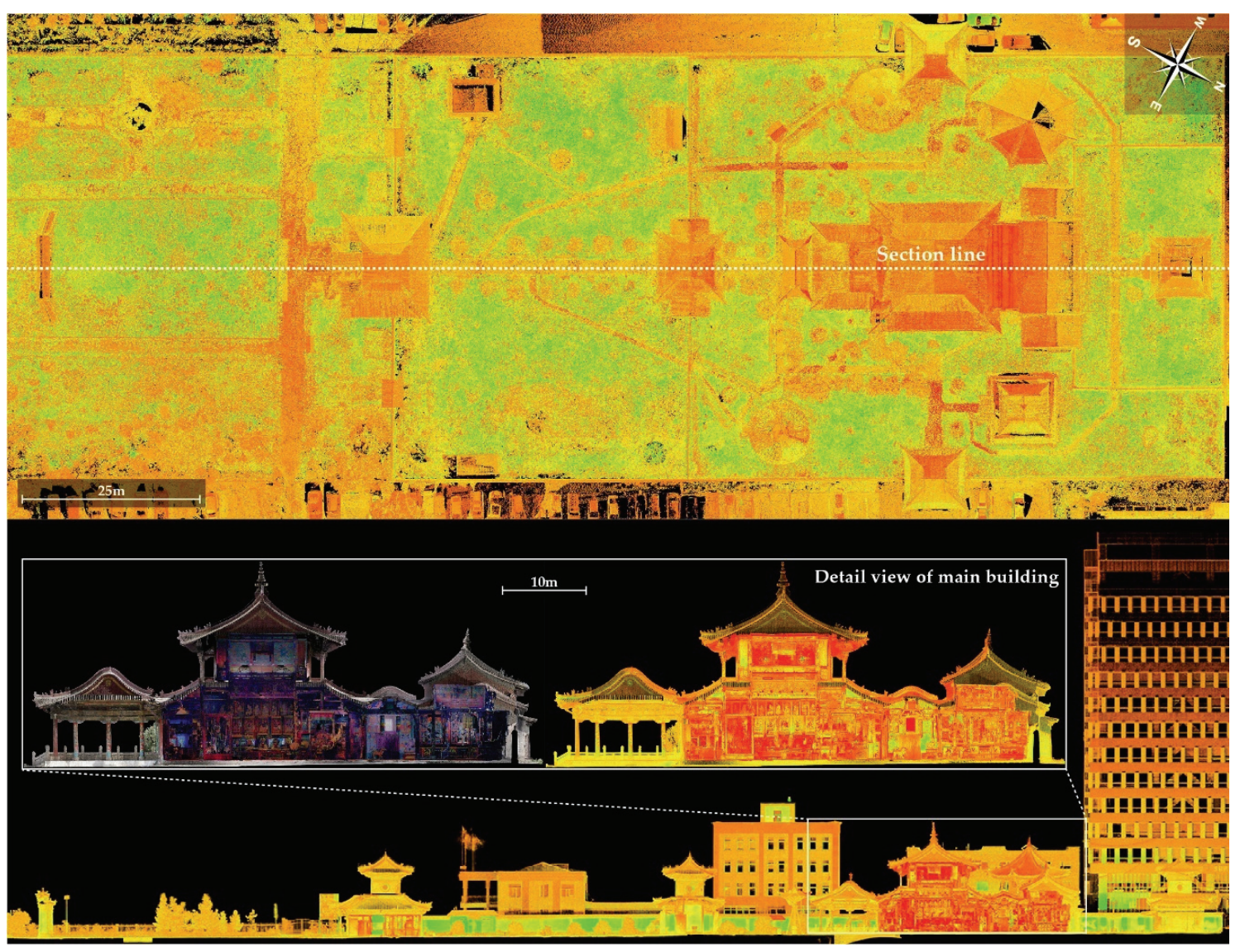

Figure 6. Orthoimage and cross-section view of the Choijin Lama Temple created via terrestrial laser scanning.

of near-level land has its precincts enclosed by a wall that is 2.6-2.8 $\mathrm{m}$ high. Its buildings are distributed along two perpendicular axes and are precisely aligned with them. The temple is approximately $61 \mathrm{~m}$ wide and $175 \mathrm{~m}$ long overall and is divided into two sections by the Maharaja building $(14.4 \times 10.7 \times 11.8 \mathrm{~m})$. The Maharaja building stands at approximately $56 \mathrm{~m}$ from the shield wall fronting the temple. The main building area is approximately $119 \mathrm{~m}$ long (Figure 6). The main building is a two-story structure comprising three areas: a front section $(13.2 \times 9.7 \times 8.4 \mathrm{~m})$, a middle section $(19.2 \times 19.4 \times 16.0 \mathrm{~m})$, and a rear section $(23.4 \times$ $13.0 \times 10.5 \mathrm{~m})$.

\subsection{UAV photogrammetry}

Exclusively documenting the shape of the entire temple site and its surroundings through terrestrial laser scanning is difficult because the scanner accessibility is low (e.g., roof of a building). In contrast, UAV photogrammetry provides some alternative advantages and has a higher planar data acquisition rate in upper zones than terrestrial laser scanning (Fernández-Lozano and Gutiérrez-Alonso, 2016). The superior mobility and accessibility of UAV must be actively utilized to overcome the laser scanning disadvantages (Jo and Hong, 2019). The 3D modeling for the entire temple site was conducted using UAV photogrammetry to increase the continuous digital documentation and spatial monitoring.

First, two UAV flight plans were determined for the southeastern and northwestern territories of the Choijin Lama Temple. Next, the flight ranges and the following conditions were input into a software: camera angle $=90^{\circ}$; altitude $=23 \mathrm{~m}$; overlap $=80 \%$; sidelap $=60 \%$; and flight speed $=3 \mathrm{~m} / \mathrm{s}$ (Table 1). The UAV was then flighted under autonomous control according to the preset path. Some vertical images of the main building were acquired through manual flight and photographing for stable data processing. 
Table 1. UAV Flight parameters and conditions

\begin{tabular}{cc}
\hline Parameters & Conditions \\
\hline Camera angle & $90^{\circ}$ \\
Average flying height & $23 \mathrm{~m}$ \\
Overlap & $80 \%$ \\
Sidelap & $60 \%$ \\
Flight speed & $3 \mathrm{~m} / \mathrm{s}$ \\
Focal length & $24 \mathrm{~mm}$ \\
Image resolution & $5472 \times 3648$ \\
Number of images & 535 \\
\hline
\end{tabular}

Two algorithms are generally used for the data processing of photogrammetry. The first step in the scale-invariant feature transform is finding a dominant gradient direction. The structure from motion is then used to properly estimate the $3 \mathrm{D}$ structures from two-dimensional image sequences that may be coupled with local motion signals. The photogrammetry data processing of the Choijin Lama Temple involved aligning 535 images, inputting GCP, reconstructing images, building point clouds, and mapping RGB textures (Figure 7).

The UAV photogrammetry result of the Choijin Lama Temple showed high-resolution point clouds, a polygon mesh, and texture mapping models. The data acquisition rate in the planar direction and the realistic effects were particularly higher for UAV photogrammetry than for terrestrial laser scanning. However, the UAV photogrammetry model did not have perfectively vertical geometric information because the camera angle of the UAV was mostly set up $90^{\circ}$ through the autonomous flight. The analysis of the average point distance for the representative sections showed that roofs A1 to A5 had distances of 7.6, 7.3, 7.1, 7.4, and $6.6 \mathrm{~mm}$, respectively, whereas the perpendicular sections B1 to B4 had a distance of 8.4, 7.9, 7.8 , and $8.0 \mathrm{~mm}$, respectively (Figure 8 ). The overall point density appeared to be similar within $10 \mathrm{~mm}$.

\subsection{Accuracy analysis}

A 3D digital documentation of cultural heritage sites, including multiple buildings, can be accomplished by integrating terrestrial laser scanning and UAV photogrammetry (Yastikli, 2007; Alshawabkeh et al., 2020). The data acquisition rates of terrestrial laser scanning and UAV photogrammetry were optimum in the perpendicular and planar directions, respectively. Therefore, the accuracy assessment between the two technologies has attracted much attention for integrated 3D modeling. This study conducted a position accuracy assessment of the point clouds obtained
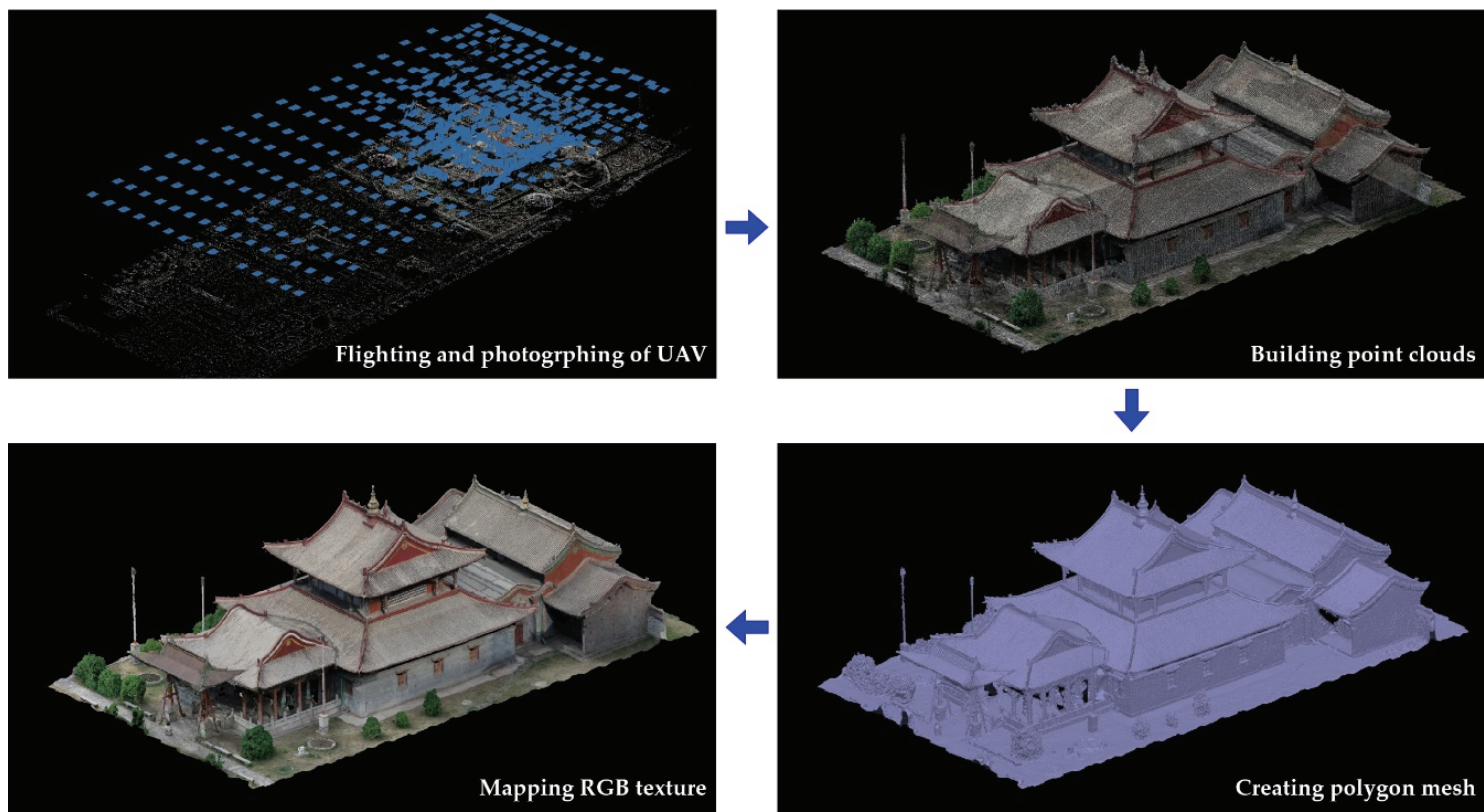

Figure 7. Data processing of UAV photogrammetry for the Choijin Lama Temple. 


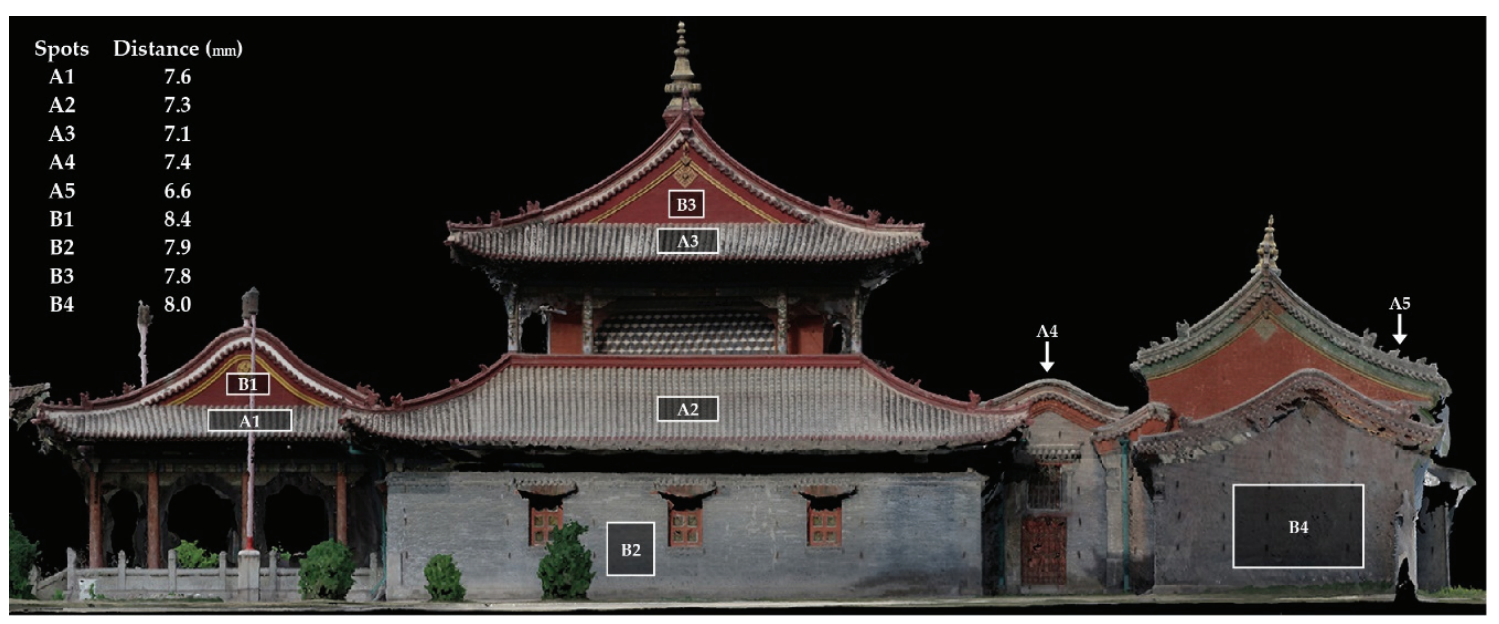

Figure 8. The average point distance of UAV photogrammetry for the representative sections of the main building.

Table 2. Relative positional coordinate discrepancies $(\mathrm{mm})$ between terrestrial laser scanning and UAV photogrammetry

\begin{tabular}{ccccccc}
\hline \multirow{2}{*}{ Point No. } & \multicolumn{3}{c}{ Ground (G) } & \multicolumn{3}{c}{ Buildings (B) } \\
\cline { 2 - 7 } & $\mathbf{X}$ & $\mathbf{Y}$ & $\mathbf{Z}$ & $\mathbf{X}$ & $\mathbf{Y}$ & $\mathbf{Z}$ \\
\hline 1 & -0.021 & -0.047 & -0.006 & -0.020 & -0.035 & -0.014 \\
2 & -0.018 & -0.044 & 0.000 & -0.019 & 0.003 & 0.015 \\
3 & -0.012 & -0.039 & -0.015 & -0.003 & -0.022 & -0.010 \\
4 & -0.015 & -0.037 & -0.011 & -0.031 & -0.043 & -0.017 \\
5 & -0.001 & -0.036 & -0.014 & -0.030 & -0.034 & 0.002 \\
6 & -0.020 & -0.011 & -0.006 & -0.006 & -0.012 & 0.005 \\
7 & 0.009 & -0.039 & 0.025 & -0.043 & 0.003 & -0.012 \\
8 & -0.011 & -0.007 & -0.010 & -0.007 & 0.009 & 0.013 \\
9 & -0.021 & -0.001 & -0.012 & -0.036 & -0.017 & -0.010 \\
10 & -0.014 & -0.020 & -0.026 & 0.009 & 0.006 & -0.041 \\
\hline Mean & -0.012 & -0.028 & -0.008 & -0.019 & -0.014 & -0.007 \\
\hline RMS & 0.015 & 0.032 & 0.014 & 0.024 & 0.022 & 0.016 \\
\hline
\end{tabular}

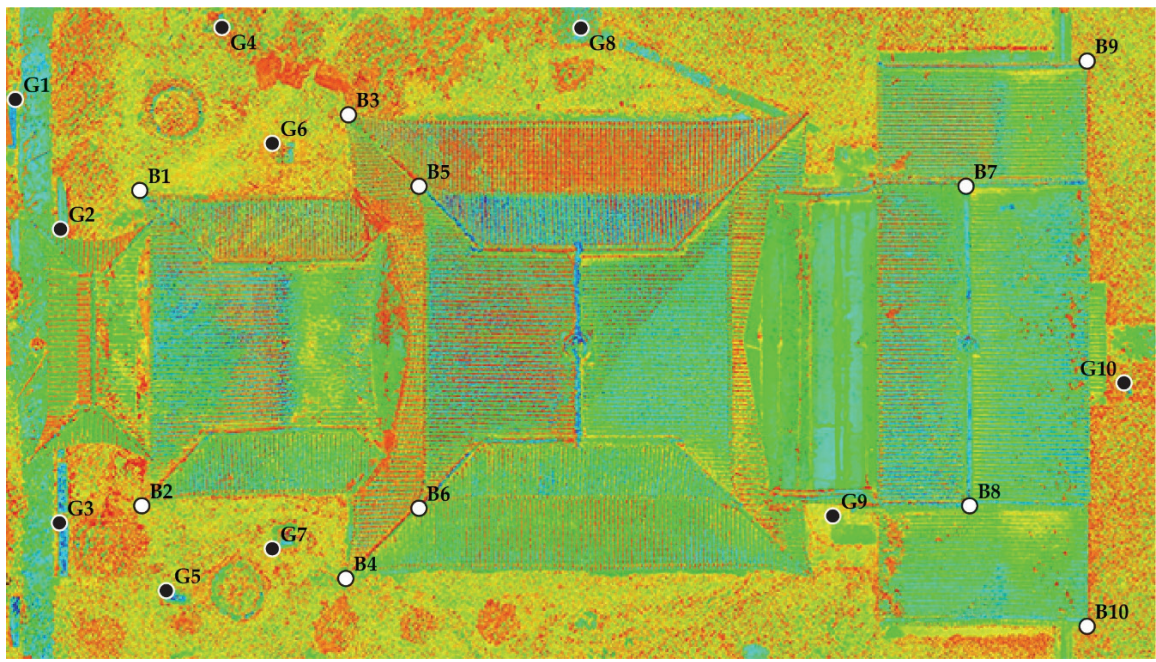

Figure 9. A total of 20 randomly selected points on the ground and buildings for analysis of the relative positional accuracy between terrestrial laser scanning and UAV photogrammetry. 

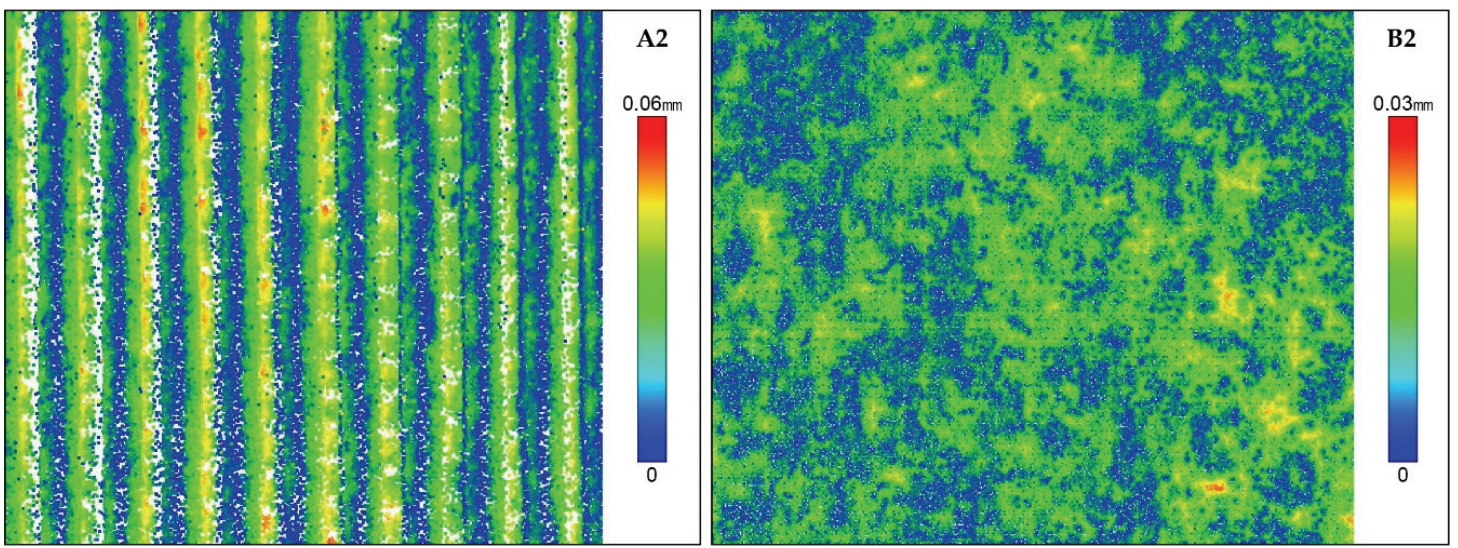

Figure 10. Deviation mapping results of the roof (A2) and masonry wall (B2).
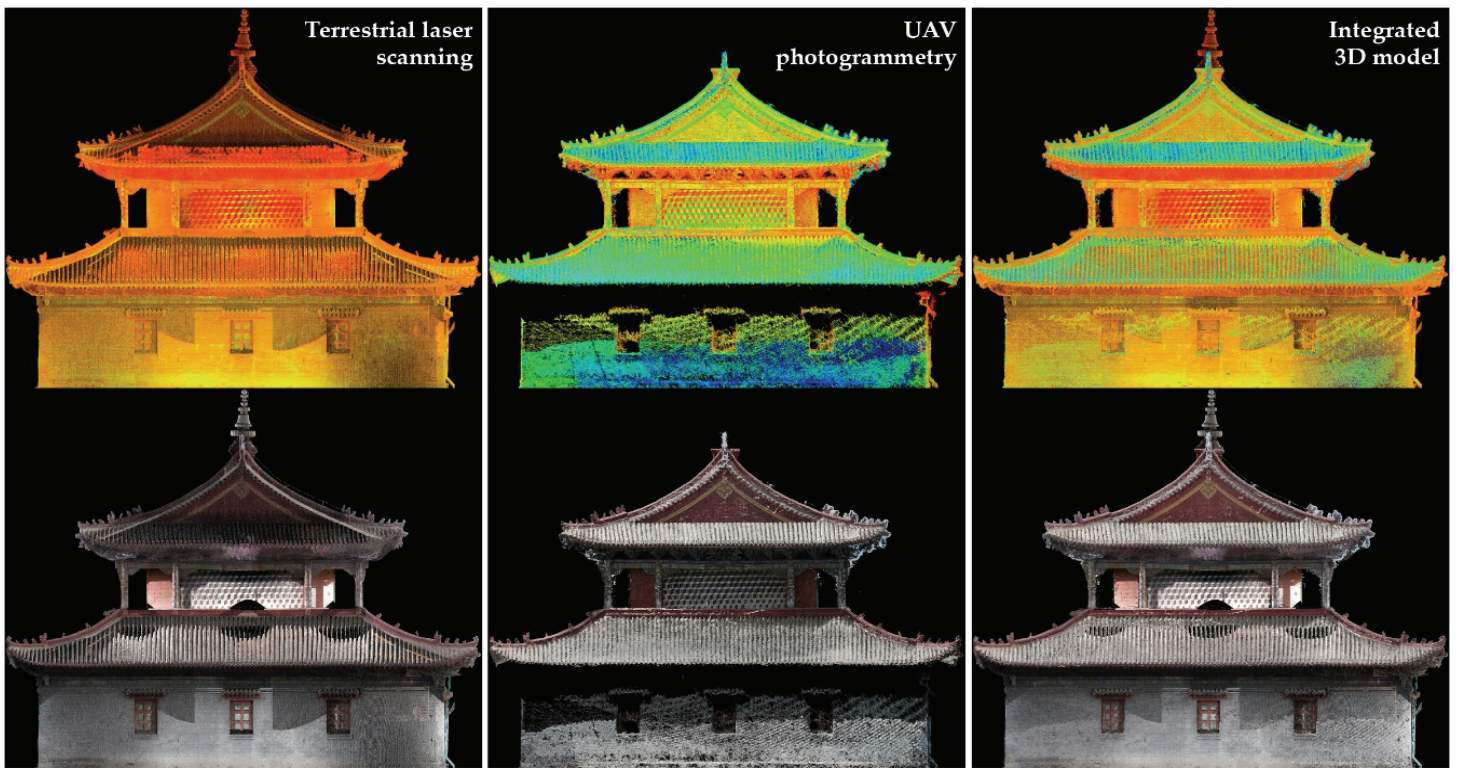

Figure 11. Process and result of integrated 3D modeling.

from these two digital technologies.

To achieve this goal, the relative positional accuracy of UAV photogrammetry based on terrestrial laser scanning was analyzed using randomly selected points considering height. The coordinate discrepancies were calculated at 20 points on the ground and roof of buildings (Figure 9). The maximum negative and positive difference values on the ten ground points were -0.021 to $0.009 \mathrm{~m}$ in the $\mathrm{X}$ coordinate (RMS: $0.015 \mathrm{~m}$ ), -0.047 to $-0.001 \mathrm{~m}$ in the $\mathrm{Y}$ coordinate (RMS: $0.032 \mathrm{~m}$ ), and -0.026 to $0.025 \mathrm{~m}$ in the $\mathrm{Z}$ coordinate (RMS: $0.014 \mathrm{~m}$ ), respectively (Table 2). Furthermore, the $\mathrm{X}, \mathrm{Y}$, and $\mathrm{Z}$ coordinates on the buildings deviated in the range of -0.043 to $0.009 \mathrm{~m}$ (RMS: $0.024 \mathrm{~m}$ ), -0.043 to $0.009 \mathrm{~m}$ (RMS: $0.022 \mathrm{~m}$ ), and -0.041 to $0.015 \mathrm{~m}$ (RMS: $0.016 \mathrm{~m}$ ), respectively (Table 2). Overall, the differences of the coordinates were less than $\pm 0.03 \mathrm{~m}$ on the ground and $\pm 0.02 \mathrm{~m}$ on the buildings. Significantly higher deviations were obtained in the negative direction. The point cloud comparison was an effective approach for investigating the correspondence of the terrestrial laser scanning and UAV photogrammetry methods.

Besides the point analysis, detailed and macroscopic deviations between the terrestrial laser scanning and UAV photogrammetry models were mapped on the roof and masonry wall. Consequently, the roof and the ground showed 0.032 and $0.036 \mathrm{~m}$ at the maximum deviation and 0.011 and $0.08 \mathrm{~m}$ at the RMS, respectively (Figure 10). These results 
indicate that no major differences existed in the deviation values between terrestrial laser scanning and UAV photogrammetry. Figure 11 shows the $3 \mathrm{D}$ point cloud combined with the UAV photogrammetry result based on the terrestrial laser scanning model. In summary, the integrated 3D model helps overcome the limitations of data acquisition through a single technology.

\section{CONCLUSION}

The Choijin Lama Temple reflected Chinese and Mongolian architectural methods considering styles similar to surrounding countries. Among the various documentation methods available (e.g., manual survey, aerial photography, and rubbing), this study digitalized in detail the main building and entire temple site of the Choijin Lama Temple using 3D scanning as part of the Korea-Mongolia Architectural Cultural Heritage Documentation Project. Various geometric information, including building structure, brackets, and surrounding environment, can be established through a completed 3D model.

Long-range terrestrial laser scanning was conducted for the $3 \mathrm{D}$ digital model of the entire temple site, which showed 4.0 to $46.0 \mathrm{~mm}$ resolutions, although they differed according to location and direction. The main building's interior was also digitalized using mid-range scanning with high- resolution data. 3D scanning is the optimum method for digitalizing current states and conditions because it obtains the raw data for measurement and documentation. Presently, digital documentation technologies, such as 3D scanning, are not universal in Mongolia. Terrestrial laser scanning can accurately and quickly acquire the geometry of a large cultural heritage site, but its applicability is relatively low in areas where the scanner is not accessible (e.g., roof of a building).

Therefore, UAV photogrammetry must be actively applied to monitor the spatial and environmental changes of the temple in the medium to longer term. Various countries including Korea, have applied UAV photogrammetry for official development assistance because of its superior mobility and accessibility as well as low cost. The UAV photogrammetry result was not utilized herein as the raw data for the digital documentation of the Choijin Lama Temple, but the data reliability was verified through an accuracy assessment compared with terrestrial laser scanning. The relatively low RMSE of UAV photogrammetry from the ground to the uppermost roof indicated the high applicability of UAV photogrammetry for integration with the terrestrial laser scanning model. Thus, the accuracy level of the two technologies is high enough to be widely used in the digital documentation and conservation as well as in building information modeling.

This study did not perfectly digitalize the entire temple site because of the short field scan time and insufficient understanding of culture. The internal 3D scan for other wooden buildings was not completed, except for the main building. However, digitalizing the Choijin Lama Temple through the Korea-Mongolia joint project, which is a representative Mongolian ancient temple, is expected to have a great ripple effect on the documentation, conservation, and utilization of Mongolian cultural heritage sites. Therefore, this study has made a significant contribution to set the education and universalization of digital technologies in the future.

\section{ACKNOWLEDGMENTS}

This paper was funded by the National Research Institute of Cultural Heritage of Korea (A Study on the Architectural Heritage Techniques) and was supported by Basic Science Research Program through the National Research Foundation of Korea (NRF) funded by the Ministry of Science, ICT \& Future Planning (NRF-2016R1C1B2010883).

\section{REFERENCES}

Alshawabkeh, Y., El-Khalili, M., Almasri, E., Bala'awi, F. and Al-Massarweh, A., 2020, Heritage documentation using laser scanner and photogrammetry. The case study of Qasr Al-Abidit, Jordan. Digital Applications in Archaeology and Cultural Heritage, 16, e00133.

Campiani, A., Lingle, A. and Lercari, N., 2019, Spatial analysis and heritage conservation: leveraging 3-D data and GIS for monitoring earthen architecture. Journal of Cultural Heritage, 39, 166-176.

Dalkılıç, N. and Nabikoğlu, A., 2020, Documentation and analysis of structural elements of traditional houses for conservation of cultural heritage in Siverek (Şanlıurfa, Turkey). Frontiers of Architectural Research, 9(2), 385402.

Fernández-Lozano, J. and Gutiérrez-Alonso, G., 2016, Improving archaeological prospection using localized UAVs assisted photogrammetry: an example from the Roman 
Gold District of the Eria River Valley (NW Spain). Journal of Archaeological Science: Reports, 5, 509-520.

Ferraby, R. and Powlesland, D., 2019, Heritage and landscape change: recording, archiving and engaging with photogrammetry on the Jurassic Coast World Heritage Site. Proceedings of the Geologists' Association, 130 (3-4), 483-492.

Guan, H., Su, Y., Sun, X., Xu, G., Li, W., Ma, Q., Wu, X., Wu, J., Liu, L. and Guo, Q., 2020, A marker-free method for registering multi-scan terrestrial laser scanning data in forest environments. ISPRS Journal of Photogrammetry and Remote Sensing, 166, 82-94.

Jeong, G.Y., Nguyen, T.N., Tran D.K. and Hoang, T.B.H., 2020, Applying unmanned aerial vehicle photogrammetry for measuring dimension of structural elements in traditional timber building. Measurement, 153, 107386.

Jo, Y.H. and Hong, S., 2019, Three-dimensional digital documentation of cultural heritage site based on the convergence of terrestrial laser scanning and unmanned aerial vehicle photogrammetry. International Journal of Geo-Information, 8, 53.

Jo, Y.H. and Lee, C.H., 2009, 3D Image Analysis for Digital Restoration and Structural Stability Evaluation of Stone Cultural Heritage: five-storied Magoksa Temple Stone Pagoda. Journal of Conservation Science, 25(2), 115-130. (in Korean with English abstract)

Jo, Y.H. and Lee, C.H., 2012, Three-dimensional Digital Restoration and Surface Depth Modeling for Shape Analysis of Stone Cultural Heritage: Haeundae Stone Inscription. Journal of Conservation Science, 28(1), 87-94. (in Korean with English abstract)
Kioussi, A., Karoglou, M., Labropoulos, K., Bakolas, A. and Moropoulou, A., 2013, Integrated documentation protocols enabling decision making in cultural heritage protection. Journal of Cultural Heritage, 14(3), e141e146.

National Research Institute of Cultural Heritage, 2019, Mongolian national architecture: Choijin Lama Temple. 4, 1-348.

O'Driscoll, J., 2018, Landscape applications of photogrammetry using unmanned aerial vehicles. Journal of Archaeological Science: Reports, 22, 32-44.

Wilson, L., Rawlinson, A., Frost, A. and Hepher, J., 2018, 3D digital documentation for disaster management in historic buildings: applications following fire damage at the Mackintosh building, The Glasgow School of Art. Journal of Cultural Heritage, 31, 24-32.

Yastikli, N., 2007, Documentation of cultural heritage using digital photogrammetry and laser scanning. Journal of Cultural Heritage, 8(4), 423-427.

Yang, B., Zang, Y., Dong, Z. and Huang, R., 2015, An automated method to register airborne and terrestrial laser scanning point clouds. ISPRS Journal of Photogrammetry and Remote Sensing, 109, 62-76. 